\title{
Proposal of Index of Cyclic Material Use in Green Environmental Profiles
}

\author{
Akira Shiga $^{* 1}$ and Osamu Umezawa*2 \\ Division of Mechanical Engineering and Materials Science, Graduate School of Engineering, \\ Yokohama National University, Yokohama 240-8501, Japan
}

The author has developed a method for evaluating green environmental profiles. In the definition of eco-efficiency, the factors responsible for any kind of environmental burden were clarified. The eight evaluation criteria - new processes to eliminate emissions of hazardous substances; greenhouse gases; environmental emission in the atmosphere, water, and soil; industrial water; exhaust heat; and final disposal - can be used to evaluate each environmental burden. Emission targets were also specified in order to measure their achievements. The evaluation criteria include DfE (Design for Environment) support information for manufacturing, recycling, and disposal processes in the eco-efficiency equation. Achievement in every criterion is classified using an evaluation sheet developed for the purpose. [doi:10.2320/matertrans.MK200711]

(Received July 3, 2007; Accepted September 26, 2007; Published November 25, 2007)

Keywords: benign manufacture, emission, environmental burden, final disposal, pollution

\section{Introduction}

A NEDO grant project entitled International Development and Standardization of Environmental Information Indices of Materials ${ }^{1)}$ was launched in the year 2005 to develop the indices for disclosing environmental information of traded materials and to standardize these materials internationally for the purpose of purchase and sale. In order to reduce the environmental burden of industrial products, six environmental information indices have been proposed, and these indices are classified into three groups: (1) resources (resources causing low environmental burden and high recycling efficiency), (2) manufacture, use, and disposal (high productivity in use and green environmental profiles), and (3) safety (reduce hazardous chemical substances and high cleaning efficiency). The indices in the framework will be shown as a radar chart.,2) These indices are used as indicators to evaluate performance of materials and it is hoped that they will help to establish new industries with a novel environmental technology. When the environmental information indices of materials are developed and promoted, high eco-efficiency materials (ecomaterials) become internationally competitive, and the development of such ecomaterials is promoted. Widespread use of ecomaterials in free trade area will reduce the environmental burden of industrial products on a global scale.

In the second group, we have focused on the index in green environmental profiles. In other words, we attempt to determine whether or not materials are fabricated, processed to manufacture products, and recycled or disposed in the processes causing low environmental burden. The index covers the following subjects:

1) Introduction of a new process to eliminate production of hazardous substances at the manufacturing stage

2) Reduction of $\mathrm{CO}_{2}, \mathrm{SO}_{X}$, and $\mathrm{NO}_{X}$ emissions; pollution of air, water, and soil; and waste matters

3) Reduction of the amount of disposal These provide the information that supports the DfE (Design for Environment) as well as other indices in both increasing

\footnotetext{
${ }^{* 1}$ Present address: Sumitomo Metals Industry

${ }^{* 2}$ Corresponding author, E-mail: umezawa@ynu.ac.jp
}

recycling efficiency and reducing hazardous chemical substances. However, it is difficult to evaluate these indices quantitatively. Then, we have discussed the equation of ecoefficiency, which is divided into countable and uncountable factors. In the present study, the index in green environmental profiles has been defined in the equation of eco-efficiency to build a framework for assessment. In other words, we have proposed a classification for the evaluation criteria and the evaluation sheet in order to evaluate as an environmental information index.

\section{Definition of Eco-Efficiency and Environmental Bur- den}

Eco-efficiency is defined by eqs. (1) and (2) as follows: $:^{3,4)}$

$$
\begin{aligned}
& \text { Eco-efficiency }=\frac{\text { Performance }}{E B_{\text {total }}} \\
& E B_{\text {total }}=\left(1+\frac{\text { emission }_{\text {total }}}{\text { product }}\right) \times E B_{\text {resource }}
\end{aligned}
$$

where $E B_{\text {total }}$ is the environmental burden of a product in the life cycle, and $E B_{\text {resource }}$ is one of the resources used for it. In order to distinguish between the countable and uncountable factors, the equation (1) is developed as follows:

$$
\begin{aligned}
& \text { Eco-efficiency } \\
& \cong \frac{\text { performance }}{\text { property }} \times \frac{\text { property }}{\text { material }} \times \frac{\text { material }}{\text { raw-material }} \\
& \times\left[(1-x) \times \frac{\text { raw-material }}{\text { resource }_{\text {natural }}} \times \frac{\text { resource }_{\text {natural }}}{E B_{\text {natural-resource }}}\right. \\
& \left.+x \times \frac{\text { raw-material }}{\text { resource }_{\text {recycle }}} \times \frac{\text { resource }_{\text {recycle }}}{E B_{\text {recycle-resource }}}\right] \\
& \times \frac{E B_{\text {resource }}}{E B_{\text {total }}}
\end{aligned}
$$

where $\mathrm{x}$ is recycle rate, both raw-material/resource natural (natural resource) and raw-material/resource recycle $_{\text {(recycled }}$ resource) are yield rate, $E B_{\text {natural resource }}$ is the environmental burden of the natural resources, $E B_{\text {recycle resource is the }}$ environmental burden of the recycled resources, resource $_{\text {natural }} / E B_{\text {natural resource }}$ is equal to $1 / T M R$, and resource $_{\text {recycle }} / E B_{\text {recycle resource }}$ is equal to 1 . TMR stands for 
Table 1 A list of evaluation criteria for estimating the environmental burden.

\begin{tabular}{|c|c|c|c|c|c|c|}
\hline Process & $\begin{array}{l}\text { Natural } \\
\text { resource }\end{array}$ & $\begin{array}{c}\text { Material } \\
\text { manufacturing }\end{array}$ & $\begin{array}{c}\text { Product } \\
\text { manufacturing }\end{array}$ & $\begin{array}{l}\text { Recycle } \\
\text { resource }\end{array}$ & Disposal & Land fill \\
\hline \multirow{3}{*}{ Manufacturing } & \multicolumn{5}{|c|}{ New processes to remove hazardous substances } & \\
\hline & \multicolumn{4}{|c|}{$\begin{array}{l}\text { Greenhouse gases } \\
\text { Environmental emission in the atmosphere, water, and soil }\end{array}$} & Final disposal & \\
\hline & & & & \multicolumn{2}{|c|}{$\begin{array}{l}\text { Industrial water } \\
\text { Exhaust heat }\end{array}$} & \\
\hline \multirow[t]{2}{*}{ Recycling } & & & & \multicolumn{2}{|c|}{$\begin{array}{l}\text { Emission in the atmosphere, } \\
\text { water, and soil }\end{array}$} & \\
\hline & & & & & Final disposal & \\
\hline Disposing & & & & & \multicolumn{2}{|c|}{$\begin{array}{l}\text { Emission in the atmosphere, } \\
\text { water, and soil Final disposal }\end{array}$} \\
\hline
\end{tabular}

Table 2 Classification of the evaluation criteria.

\begin{tabular}{cll}
\hline Grade & \multicolumn{1}{c}{ Item } & \multicolumn{1}{c}{ Reference } \\
\hline 1 & New processes to remove hazardous substances & Environmental Reporting \\
\cline { 2 - 3 } & Greenhouse gases & Kyoto and Oslo protocols \\
\cline { 2 - 3 } & Environmental emissions in the atmosphere & Kyoto and Oslo protocols \\
& Environmental emissions in water & Persistent Organic Pollutants (Stockholm convention) \\
\hline & Environmental emissions in soil & Persistent Organic Pollutants (Stockholm convention) \\
\hline & Industrial water & Environmental Reporting \\
\hline & Exhaust heat & Environmental Reporting \\
\hline \multirow{2}{*}{3} & Final disposal & Environmental Reporting \\
& & Basel Convention
\end{tabular}

the total material requirement, details of which are provided elsewhere. ${ }^{5)}$ The uncountable factor in the eq. (3) is approximated as follows:

$$
\begin{aligned}
\frac{E B_{\text {resource }}}{E B_{\text {total }}}= & \frac{(1-x) T M R+x}{E B_{\text {total }}} \\
E B_{\text {total }}= & (1-x)\left(T M R+E B_{\text {natural-resource }}\right) \\
& +x\left(1+E B_{\text {recycle-resource }}\right) \\
& +E B_{\text {material-manufacturing }}+E B_{\text {product-manufacturing }} \\
& +E B_{\text {in-use }}+E B_{\text {disposal }}+E B_{\text {land-fill }}
\end{aligned}
$$

In eq. (5), $E B$ factors are uncountable, and the related processes are summarized in Table 1 . The evaluation criteria are also listed in Table 1. The indices for increased productivity in use and reduced hazardous chemical substances take into account the $E B_{\text {in-use }}$ and $E B_{\text {landfill }}$, respectively. Others are involved in the green environmental profiles.

\section{Procedure}

\subsection{Evaluation criteria}

Eight checking items have been proposed as listed in Tables 1 and 2. All criteria are evaluated on a scale of 10 to 1 through a self-declaration question sheet. The declaration should be based on evidences such as environmental white paper, environmental reporting, and international protocols as summarized in Table 2.

\subsection{Indications and score calculation}

We attempt to classify the factors into three groups (i.e., grades 1,2, and 3) since all factors may not have an equal impact on the environment. Each group has a different importance number for following evaluation is given in each group. The ratings on the scale of 10 to 1 are colored differently and indicated in a leaf form. Eight leaves compose a tree mark, and we can visually recognize the green environmental profile of materials used in a product as a color distribution of the leaves on the tree mark (Fig. 1). The "total" number shown in Fig. 1 provides the index score of the green environmental profiles and is calculated using equation (6) as follows:

$$
\text { total }=\frac{3 \times \text { score } 1+2 \times \text { score } 2+1 \times \text { score } 3}{6}
$$

where "score 1" is the average number of Grade 1; "score 2," the average number of Grade 2; and "score 3," the average number of Grade 3. A score between 1 and 10 relating to each factor is given to aid selection of a particular technique. The factors are temporally set as simple numbers based on the priority of groups to encourage the process innovation for lower environmental burden. But the factors should be based on the results of a customer survey, where up-to-date information about each individual change is necessary to install them with an agreement from all stakeholders including representatives from the public. 

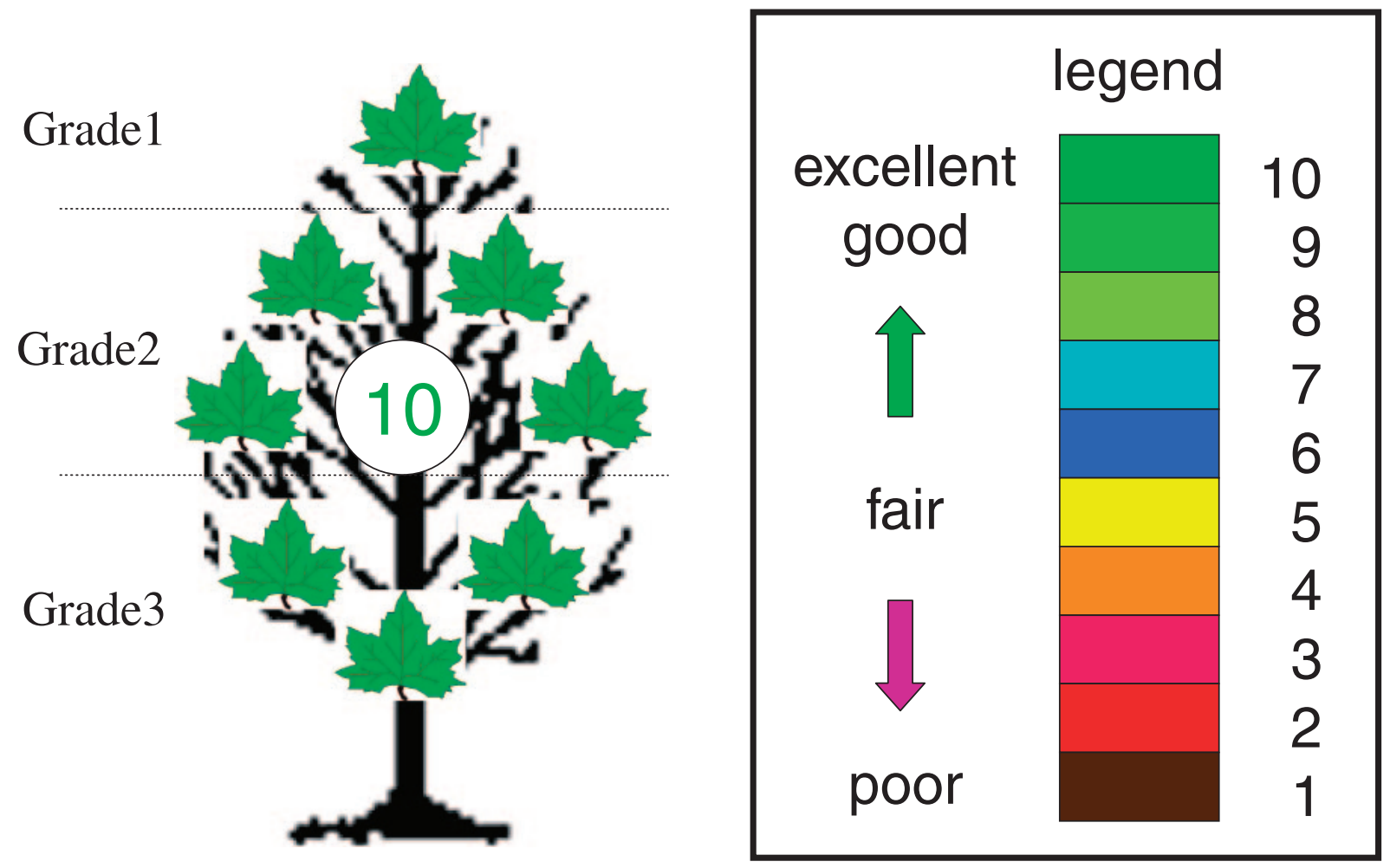

Fig. 1 An example of schematic indication and evaluation.

\subsection{Emission target}

The target set by the Kyoto and Oslo protocols on greenhouse gases (e.g., $\mathrm{H}_{2} \mathrm{O}$, tropospheric ozone, $\mathrm{CO}_{2}, \mathrm{CH}_{4}$, $\mathrm{N}_{2} \mathrm{O}, \mathrm{CFCs}$, and $\mathrm{SF}_{6}$ ) and emissions in the atmosphere is as follows:

$$
\text { Emission target }=\mathrm{C} \times(\text { production })
$$

where $\mathrm{C}$ is a constant calculated from reduction targets among the USA, the EU, and Japan. The benchmark year set by the Kyoto protocol for $\mathrm{CO}_{2}, \mathrm{CH}_{4}$, and $\mathrm{N}_{2} \mathrm{O}$ is 1990 and the year for HFC, PFC, and $\mathrm{SF}_{6}$ is 1995.

The target set for Persistent Organic Pollutants (POPs) in the Stockholm convention (e.g., aldrin, chlordane, dieldrin, endrin, heptachlor, hexachlorobenzene, mirex, toxaphene, PCB, DDT, dioxin, and dibenzofuran) was also adopted for the emissions in the atmosphere, water, and soil. For example, Table 3 shows the case of dioxin reduction in Japan in the year 2003. These targets will serve as a guideline for the evaluation of the environmental burden.

\section{Evaluation}

\subsection{New process to eliminate hazardous substances}

Challenges in developing a greener process are evaluated through questionnaires shown in Fig. 2. The purpose for placing the item in Grade 1 is to encourage and actively promote the development of greener materials and products.

\subsection{Greenhouse gases}

Figure 3 shows an example of the check sheet evaluating the emissions of greenhouse gases. The Kyoto protocol provides guidelines based on the kinds of greenhouse gases. Barring moisture, the gases that affect the climate are as
Table 3 Percentage targeted dioxin reduction in Japan in the year 2003.

\begin{tabular}{|c|c|c|c|c|}
\hline \multicolumn{2}{|c|}{ Waste disposal } & \multicolumn{2}{|c|}{ Manufacturing } & Others \\
\hline \multicolumn{2}{|c|}{$22-25$} & \multicolumn{2}{|c|}{2} & 5 \\
\hline \multicolumn{5}{|c|}{ Do you emit any hazardous substance in manufacturing? } \\
\hline \multicolumn{2}{|c|}{ Yes } & \multicolumn{2}{|c|}{ No } & \\
\hline \multicolumn{3}{|c|}{$\begin{array}{l}\text { Have you developed a new process to } \\
\text { decrease hazardous substance? }\end{array}$} & \multicolumn{2}{|c|}{$\begin{array}{l}\text { Have you install a new process to } \\
\text { eliminate the substance? }\end{array}$} \\
\hline Yes & $\stackrel{\mathrm{No}}{\longrightarrow}$ & & Yes & $\stackrel{\text { No }}{\longrightarrow} 10$ \\
\hline
\end{tabular}

Fig. 2 An example of the check sheet for adoption of a new process to eliminate hazardous substance.

follows: $\mathrm{CO}_{2}(60 \%), \mathrm{CH}_{4}(20 \%), \mathrm{N}_{2} \mathrm{O}(6 \%)$, and others $(14 \%)$.

Further, the $\mathrm{CO}_{2}$ emissions from the steel industry in major countries were roughly estimated, since they emit a large amount of $\mathrm{CO}_{2}$. Based on the $\mathrm{CO}_{2}$ emission, the basic unit for energy, and the crude steel production in Japan, ${ }^{6}$ the $\mathrm{CO}_{2}$ emissions from the steel industry in other countries were approximated with proportional to the basic unit for energy in them (Fig. 4). According to the Kyoto protocol, percentages targeted reduction of $\mathrm{CO}_{2}$ emission in USA, EU, and Japan are 7,8 , and 6 , respectively. The reduction target for each substance and social conditions for environmental technologies are different in countries. Therefore, the coefficient value of 1.5 , which is equivalent to $5 \%$ reduction of $\mathrm{CO}_{2}$ emission amounts among advanced countries (USA, EU, and Japan) in average, is given in eq. (7) as a first step target for steel industry. Not all countries have met the $\mathrm{CO}_{2}$ emission 


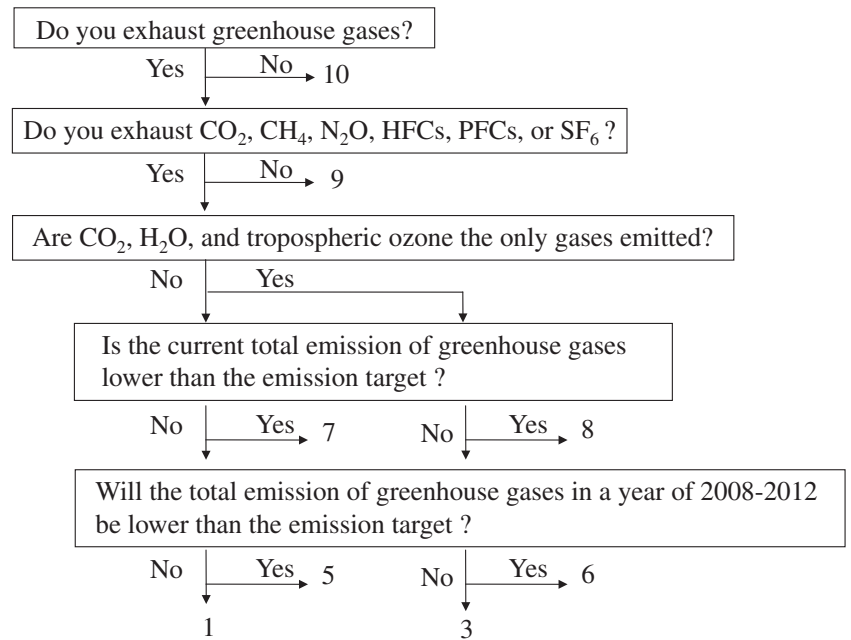

Fig. 3 An example of the check sheet for greenhouse gases.

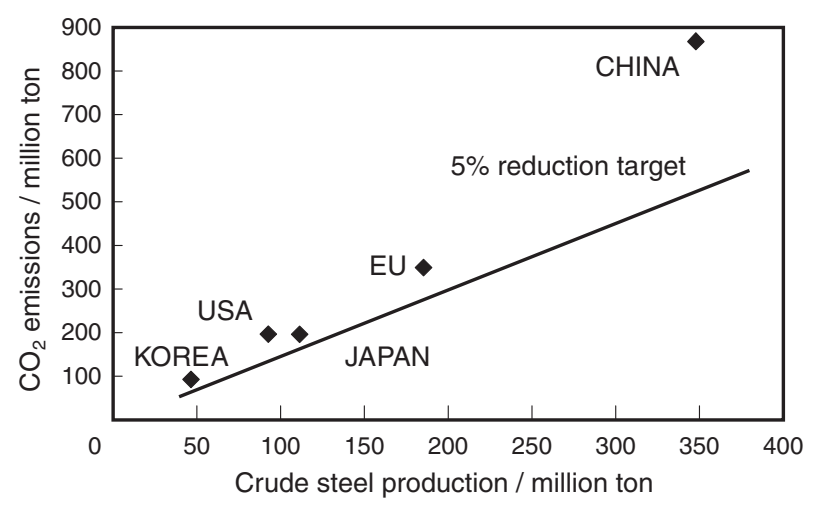

Fig. 4 Evaluation of $\mathrm{CO}_{2}$ emission by the steel industry in the year 2005 .

target set for steel industry. In particular, those in China, $\mathrm{USA}$, and EU need to make greater efforts to reduce $\mathrm{CO}_{2}$ emissions.

\subsection{Environmental emissions in the atmosphere, water, and soil}

The pollution caused by $\mathrm{NO}_{\mathrm{X}}, \mathrm{SO}_{\mathrm{X}}$, and mine dust emissions in the atmosphere is evaluated through the questions listed in Fig. 5. Figure 6 presents estimations of $\mathrm{SO}_{\mathrm{X}}$ and $\mathrm{NO}_{\mathrm{X}}$ emissions by the steel industry in major countries. The $5 \%$ reduction target lines for $\mathrm{SO}_{\mathrm{X}}$ and $\mathrm{NO}_{\mathrm{X}}$ as well as for $\mathrm{CO}_{2}$ are drawn in Fig. 6. Their coefficient values in eq. (7) are 1.3 and 0.55 . The steel industries of Japan and Korea are good measures to prevent air pollution, although percentage targeted reduction of $\mathrm{SO}_{\mathrm{X}}$ emission in Japan is 10 . Since the percentage targeted reduction of $\mathrm{SO}_{\mathrm{X}}$ emission in both USA and EU is 30, the industries in USA, EU, and China need to make greater efforts to reduce air pollution.

Release of oil, acid, alkaline solutions, and/or other pollutants into rivers, lakes, or seas were also evaluated (Fig. 7). These emissions affect not only humans but also aquatic creatures. First, each country should establish environmental standards in order to prove its commitment toward reducing water pollution. Figure 8 presents a check sheet for the emissions of volatile organic compounds (VOCs), $\mathrm{Pb}, \mathrm{Cd}, \mathrm{Hg}$, and/or other industrial pollutants in

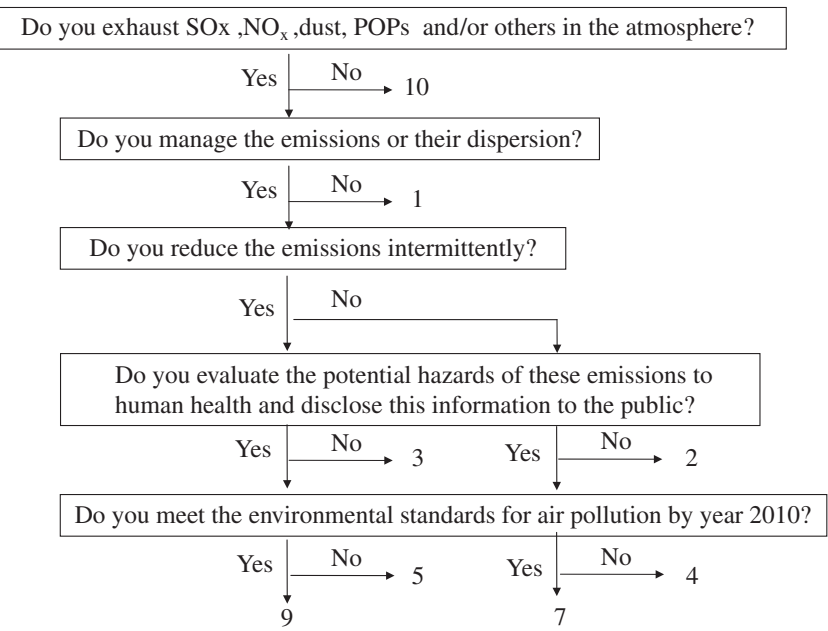

Fig. 5 An example of the check sheet for environmental emissions in the atmosphere.

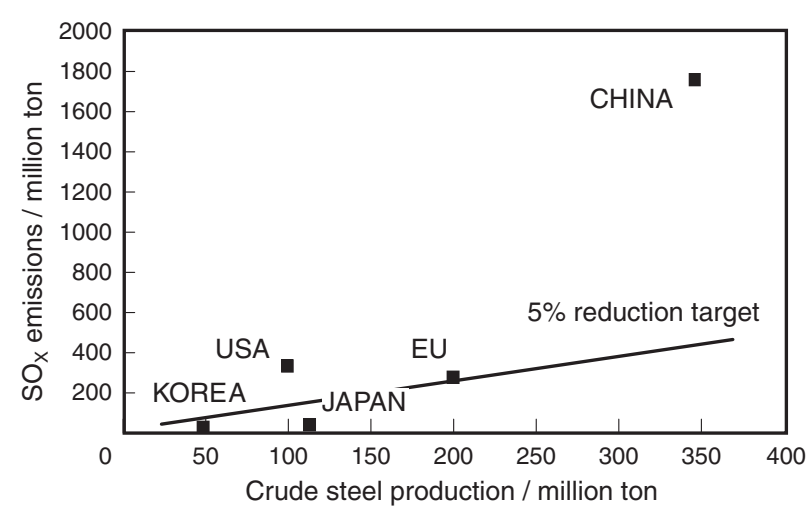

(a)

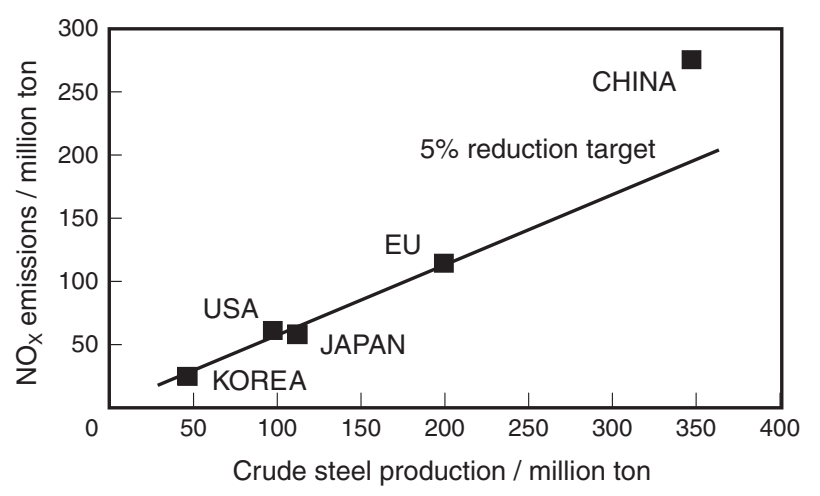

(b)

Fig. 6 Evaluation of (a) $\mathrm{SO}_{\mathrm{X}}$ and (b) $\mathrm{NO}_{\mathrm{X}}$ emissions from steel industry in the year 2005 .

the soil. The soil pollution causes water pollution and gives rise to problems in the human body, ecosystem, and farm products. Its effects are serious since recovery takes place over a long period of time.

\subsection{Treatment of industrial water, exhaust heat, and final disposal}

Industrial water and exhaust heat are types of recyclable resources, and hence, they can help in reducing the amount of 


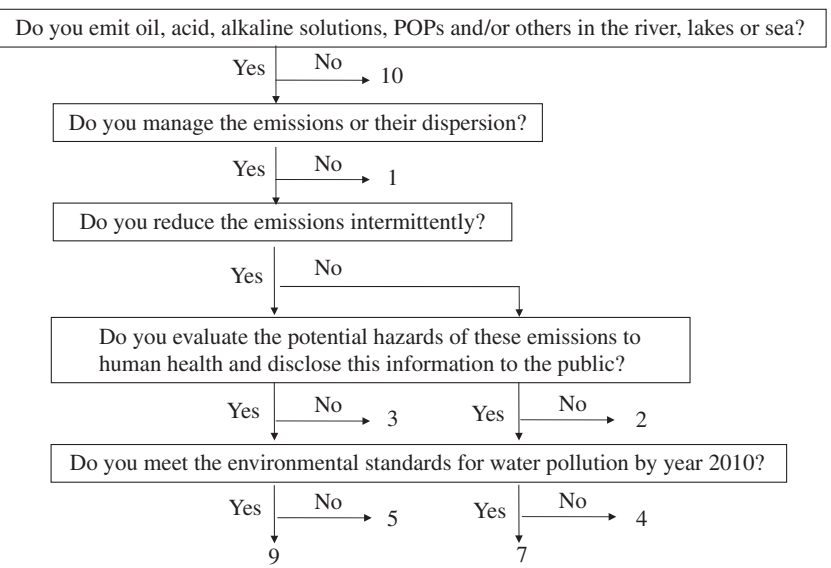

Fig. 7 An example of the check sheet for environmental emissions into water bodies.

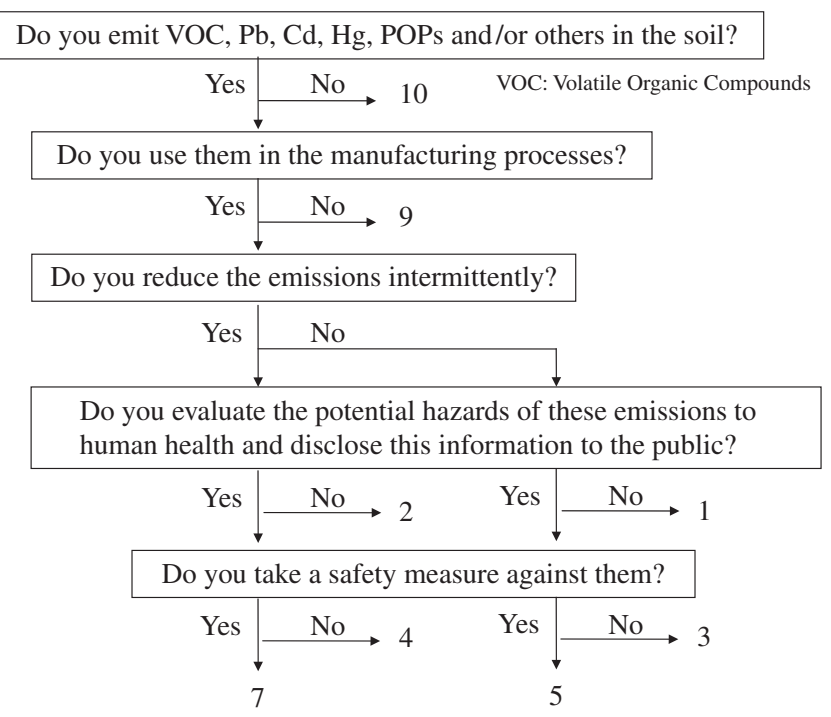

Fig. 8 An example of the check sheet for environmental emissions in soil.

final disposal. This paper also evaluates whether the industries meet the industrial water quality standards (Fig. 9). Three types of factory exhaust heat - hot gas, warm water, and heated solids - are also checked using the sheet (Fig. 10). There are roughly three methods of final disposal: (1) direct melting system, (2) incinerated ash melting, and (3) incinerated ash melting. The landfill occupations of these methods are very different from each other. The lesser the amount in landfill, the lower is the impact on the environment. This is evaluated through the check sheet (Fig. 11).

\section{Conclusions}

In this paper, the index of materials in green environmental profiles was studied as one of the six environmental information indices. The major conclusions of this study are as follows:

(1) In the definition of eco-efficiency, countable and uncountable factors were distinguished; the uncountable factors related to green environmental profiles were newly defined.

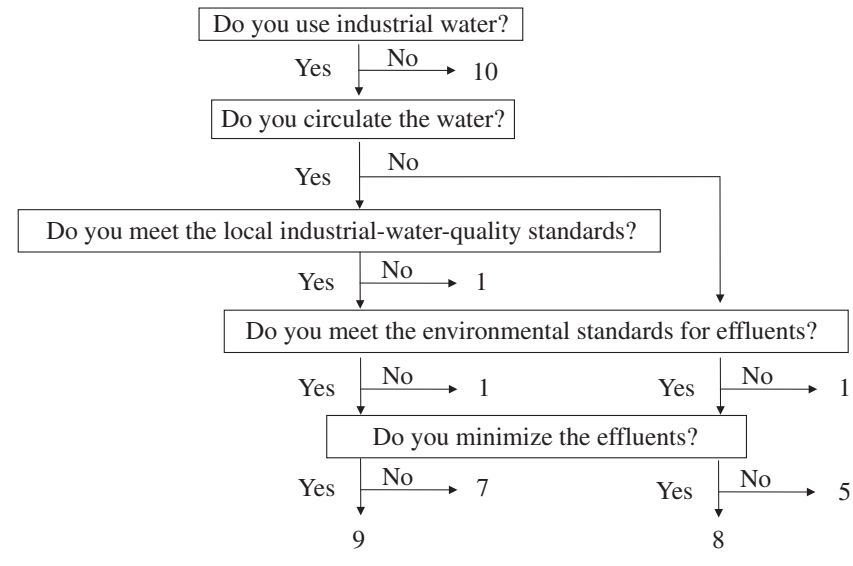

Fig. 9 An example of the check sheet for industrial water.

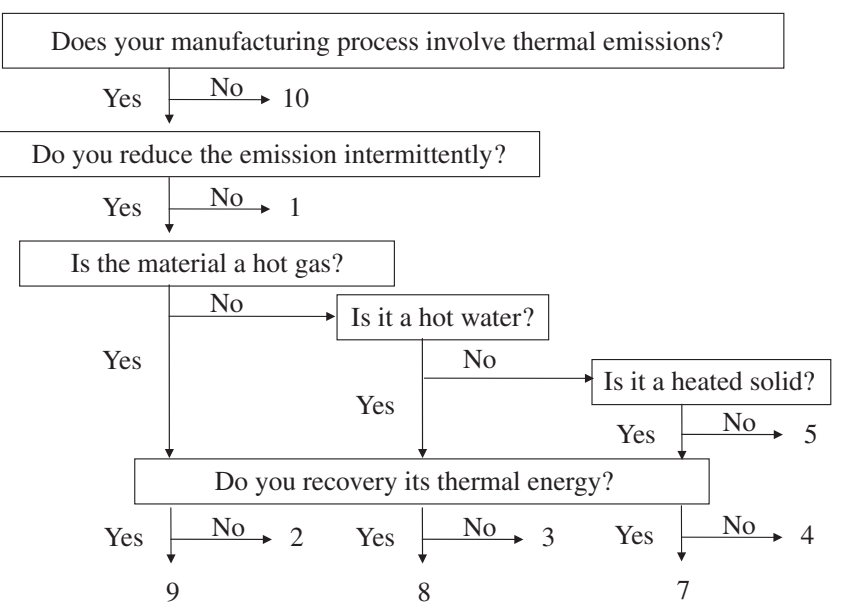

Fig. 10 An example of the check sheet for exhaust heat.

Does your manufacturing process involve a final disposal?

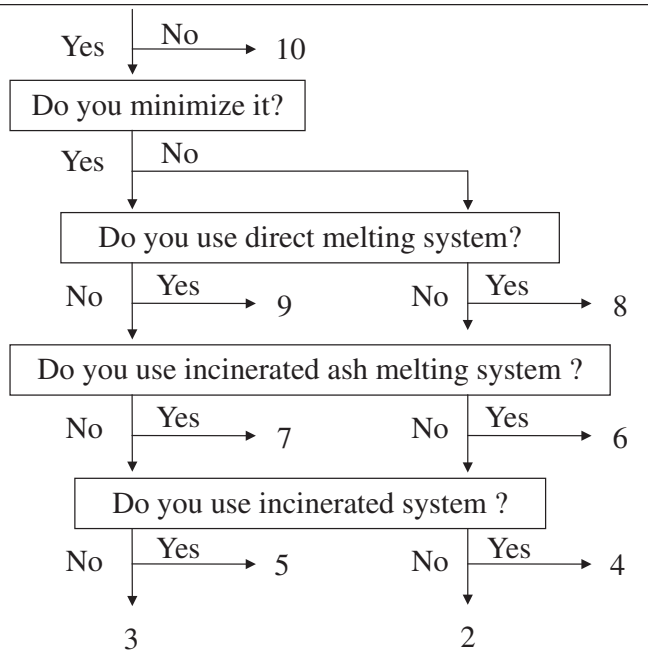

Fig. 11 An example of the check sheet for final disposal.

(2) Eight evaluation criteria and their classification into three grades have been proposed: adoption of new process to eliminate hazardous substances; greenhouse gases; environmental emissions in the atmosphere, water, and soil; industrial water; exhaust heat; and final disposal. 
(3) The evaluation criteria include the DfE support information for manufacturing, recycling, and disposal processes in the eco-efficiency equation.

(4) Achievement in every criterion is classified on a scale of 10 to 1 . We have developed the check sheets for these criteria.

\section{Acknowledgement}

This research was supported by a NEDO Grant program (2005) from the New Energy and Industrial Technology Development Organization, Japan. We thank Drs. Y. Shinohara and $\mathrm{H}$. Abe for their discussion on the definition of ecoefficiency.

\section{REFERENCES}

1) NEDO Grant program, http://www.nedo.go.jp/itd/grant-e/list/international/pdf/2005is 180.pdf.

2) O. Umezawa, K. Halada and K. Shinohara: Materials Science Forum 555 (2007) 1-7.

3) Y. Shinohara: Proc. 7th Inter. Conf. on EcoBalance, (SNTT, Tokyo, 2006), pp. 489-490.

4) Y. Shinohara: 3rd NEDO grant workshop, (SNTT, Tokyo, 2007).

5) K. Halada and K. Ijima: Proc. 7th Inter. Conf. on EcoBalance, (SNTT, Tokyo, 2006) pp. 481-484.

6) for an example, Environmental report, Nippon Steel Corp., Tokyo, (2005). 